\title{
TECNOLOGIAS PARA INVERTER A SALA DE AULA: POSSIBILIDADES DO CURRÍCULO + PARA O ENSINO DE LÍNGUA ESPANHOLA EM SÃO PAULO
}

\section{Isadora Valencise GREGOLIN*}

- RESUMO: Nesse texto, discutimos a necessidade de se pensar o trabalho com as "novas tecnologias" na perspectiva da natividade digital (PRENSKY, 2011a). Partimos do pressuposto de que as tecnologias digitais vêm imprimindo novas formas de nos relacionarmos com espaços e tempos, alterando nossas formas de socialização na web, o que demanda novas propostas pedagógicas pela escola. Para tanto, analisamos brevemente algumas atividades da plataforma Currículo+, disponibilizada pela Secretaria de Educação de São Paulo, como tecnologias com potencialidades a serem exploradas por professores de língua espanhola por meio da abordagem de aula invertida (BERGMANN; SAMS, 2012). Também discutimos a necessidade de que professores assumam para si a tarefa de produção de conteúdos educacionais, em colaboraçáo com colegas, e que contribuam com avaliação sobre o uso dos recursos, no processo de retroalimentação das plataformas e repositórios.

- PALAVRAS-CHAVE: Tecnologias. Espanhol. Aula invertida. Currículo+.

\section{Novas tecnologias e impactos no ensino}

Tem sido recorrente no Brasil, tanto na legislação educacional como nas diretrizes e orientaçôes curriculares nacionais, o incentivo ao uso de "novas tecnologias" em todas as áreas de conhecimento. Em geral, as tecnologias relacionadas com os meios de produção, circulação e comunicação em meio digital são classificadas como "novas" pois, ainda que muitas delas já estejam incorporadas às práticas cotidianas de parte da população, sua existência em relação às “outras” tecnologias é recente.

Uma das novidades dessas tecnologias consiste nas novas formas que possibilitam de nos relacionarmos com os "espaços, tempos e pelas redes", o que nos promove a possibilidade de re-pensar os papeis e funçóes dos sujeitos na sociedade, agora considerados usuários e classificados em "nativos" ou "imigrantes digitais" (PRENSKY, 2011a).

\footnotetext{
* UFSCar-Universidade Federal de São Carlos. Centro de Educação e Ciências Humanas - Departamento de Metodologia de Ensino. São Carlos - SP - Brasil. 13565-905 - isadora.gregolin@gmail.com
} 
No campo educacional, os espaços e tempos das instituiçóes escolares, tais como tradicionalmente conhecemos, permitem que professores e alunos se encontrem durante algumas horas, em diversos espaços físicos, a cada dia da semana, para trabalharem determinados tipos de conteúdos. Já no final da década de 60, essa estrutura tradicional das escolas era criticada por McLuhan e Fiore (1969, p.128), que considerava que a sala de aulas enfrentava "uma luta vital pela sobrevivência com o mundo 'exterior' imensamente persuasivo criado pelos novos meios de informação". Em outro texto, McLuhan (2005) indagava-se sobre questôes bastante atuais, tais como:

[...] o que esses meios de comunicação fazem às pessoas que os usam. O que a escrita fez às pessoas que a inventaram e a usaram? O que os outros meios de comunicaçáo de nosso tempo fazem às pessoas que os usam? Minha teoria é uma teoria da transformação, da maneira pela qual as pessoas são mudadas pelos instrumentos que empregam. (MCLUHAN, 2005, p.272).

As tentativas de expandir os limites impostos pelas configuraçóes das salas de aula tradicionais, pelo uso de recursos da web, nos sinalizam que a apropriação, pelas novas geraçóes, dos aparatos tecnológicos e de suas linguagens, conceituada por Prensky (2011a) como "natividade digital", demanda da escola novas abordagens, uma vez que a web implica novas formas de relaçóes para a cidadania.

Concordamos com a discussão de P. Freire (1996) sobre o papel transformador que a escola pode operar na realidade e consideramos atual sua análise de que:

A ideologia fatalista, imobilizante, que anima o discurso neoliberal anda solta no mundo. Com ares de pós-modernidade, insiste em convencer-nos de que nada podemos contra a realidade social que, de história e cultural, passa a ser ou a virar "quase natural". Frases como "a realidade é assim mesmo, que podemos fazer?" ou "o desemprego no mundo é uma fatalidade do fim do século" expressam bem o fatalismo desta ideologia e sua indiscutível vontade imobilizadora. Do ponto de vista de tal ideologia, só há uma saída para a prática educativa: adaptar o educando a esta realidade que não pode ser mudada. $\mathrm{O}$ de que se precisa, por isso mesmo, é o treino técnico indispensável à adaptação do educando, à sua sobrevivência. (FREIRE, P., 1996, p.10).

Não compactuamos do entendimento de que se deve utilizar novas tecnologias no ensino com a mera finalidade de motivar os alunos ou de tornar o aprendizado mais lúdico. Defendemos, sim, que a utilização das tecnologias no ensino é um direito dos alunos, pois partimos do pressuposto de que é papel da escola e da educação formal "[...] garantir aos alunos-cidadãos a formação e aquisição de novas habilidades, atitudes e valores, para que possam viver e conviver em uma sociedade em permanente processo de transformação." (KENSKI, 2007, p.64). 
Dessa forma, temos acompanhado nos últimos anos iniciativas empreendidas por docentes que buscam integrar às suas práticas pedagógicas "novos" recursos tecnológicos. Ao discutir a inserção de tecnologias pelos professores, considerados “imigrantes digitais”, Prensky (2011b) sinaliza possíveis caminhos para o trabalho com os alunos considerados "nativos digitais" e, portanto, já usuários dessas tecnologias fora da escola:

Os alunos de hoje querem aprender de maneira diferente ao passado. Querem formas de aprender que tenham significado para eles, métodos que lhes permitam ver-de imediato- que o tempo que passam em sua educação formal tem valor e que as façam bom uso da tecnologia que sabem que é de seu direito de nascença [...] Um resultado importante da introdução de tecnologia na educação de nossos jovens é a redução da distância entre aprendizado e ação significativa. Os alunos de hoje sabem que, quando aprendem algo, podem aplicá-lo depois da escola de forma imediata a uma situação real. Quando aprendem a jogar um jogo, podem colaborar e competir com outros ao redor do mundo. Quando aprendem a baixar, mandar SMS e tweets, podem participar imediatamente de profundas revoluçóes sociais, como mudar a indústria da música e influenciar em políticas do governo. Enquanto aprendem a publicar online suas criaçôes e ideias, tomam consciência de que inclusive como jovens podem influenciar verdadeiramente e mudar o mundo. Isso dá nova urgência e significado a questionamentos como "Por quê deveria aprender isso?", pergunta que nossos alunos fazem sem parar e para a qual deveríamos ter resposta melhor do que a habitual "Algum dia você precisará saber". Os alunos de hoje esperam o mesmo de sua educação formal que do resto de suas vidas, que não seja somente relevante, mas também aplicável à realidade¹. (PRENSKY, 2011b, p. 13-14, tradução nossa).

No campo específico do ensino de línguas, o desenvolvimento de tecnologias de informação e comunicação (digitais) das últimas décadas tem impulsionado experiências

\footnotetext{
Los alumnos de hoy quieren aprender de manera diferente al pasado. Quieren formas de aprender que tengan significado para ellos, métodos que les hagan ver-de inmediato- que el tiempo que pasan en su educación formal tiene valor, y formas que hagan buen uso de la tecnología que saben que es su derecho de nacimiento [...] Un resultado importante de la introducción de tecnología en la educación de nuestros niños es una reducción del margen entre aprendizaje y acción significativa. Los alumnos de hoy saben que cuando aprenden algo después de la escuela, lo pueden aplicar de forma inmediata a una situación real. Cuando aprenden a jugar un juego, pueden colaborar y competir con otros alrededor del mundo. Cuando aprenden a descargar, mandar SMS y tweets, pueden participar inmediatamente en profundas revoluciones sociales, como cambiar la industria de la música e influir en politicas del gobierno. Mientras aprenden a publicar en línea sus creaciones e ideas toman conciencia de que incluso como jóvenes pueden influir verdaderamente y cambiar el mundo. Esto da nueva urgencia y significado a "¿Por qué debería aprender esto?", pregunta que nuestros alumnos plantean sin cesar, y demanda de la que más nos valdría tener una mejor respuesta que "Algún día lo necesitarás". Los alumnos de hoy esperan lo mismo de su educación formal que del resto de sus vidas, que no sea solo relevante, sino aplicable a la realidad. . (PRENSKY, 2011b, p. 13-14).
} 
e pesquisas que evidenciam potencialidades e limites de sua utilização, dentro e fora das salas de aulas (PAIVA, 2005; LEFFA, 2006; SOTO, MAYRINK; GREGOLIN, 2009; TOMAZELLA, 2013).

Ao rechaçarmos a prática de mera transposição do ensino presencial para o meio online, tendo em vista as necessidades de adequação do ensino ao meio no qual este se realiza, concordamos com M. Freire (2009) quando esta afirma que:

Entendida como uma faceta de um processo mais abrangente, a formação tecnológica não se distancia da educação de docentes, constituindo uma vertente desta, e não um caminho paralelo. Por esse motivo, quando concebemos a formação tecnológica do professor, não podemos deixar de considerar os caminhos reflexivos que ela pode percorrer e que expóem esse profissional a novas experiências de trabalho. (FREIRE, M., 2009, p. 21).

Nesse contexto, temos desenvolvido trabalho de formação inicial de professores de língua espanhola para o desenvolvimento de competência profissional que possibilite aos futuros professores a articulação dos conteúdos abordados com os diferentes contextos de sala de aula, tendo em vista a perspectiva de que vivemos em um contexto de profundas mudanças e incertezas (IMBERNÓN, 2000).

Nossas açôes têm sido pautadas em articulação com as demandas da rede de ensino estadual paulista, sendo uma das preocupaçóes mais atuais o trabalho pedagógico com recursos e objetos disponibilizados em Portal web denominado Currículo+.

Desde 2014, a Secretaria Estadual de Educação (SEE) paulista disponibiliza, por meio do portal denominado Currículo+, conteúdos digitais, tais como vídeos, jogos, animações, simuladores, infográficos e jogos, que são previamente selecionados por uma equipe de especialistas em forma de curadoria, que os classifica em articulação com o currículo oficial de São Paulo. Todos os conteúdos são caracterizados como recursos educacionais abertos, o que significa que ou são de domínio público ou possuem licença para uso em atividades educativas. Conforme consta em sua apresentaçãó2:

O Currículo+ visa incentivar a utilização da tecnologia como recurso pedagógico articulado ao Currículo do Estado de Sáo Paulo para inspirar práticas inovadoras em sala de aula a fim de promover maior motivação, engajamento e participaçáo dos alunos com o processo educativo, visando, prioritariamente, o desenvolvimento da aprendizagem (SEE).

Levando em conta esses objetivos, o Currículo+ disponibiliza ferramenta de busca com filtros relacionados à estrutura curricular do estado de Sáo Paulo e propóe que os

2 Informação disponível em: <http://curriculomais.educacao.sp.gov.br/sobre-o-curriculo-mais/>. Acesso em: 01 fev. 2016. 
recursos sejam utilizados na perspectiva de complementar aquilo que é trabalhado no âmbito do currículo oficial.

Partimos da noção de currículo como "artefato social, concebido para realizar determinados objetivos humanos específicos” (GOODSON, 1997, p.16). Nessa perspectiva, o currículo não pode ser considerado neutro, mas é construído socialmente e evidencia "as racionalidades escolhidas" e a "retórica legitimadora das práticas escolares" (GOODSON, 1997, p.20).

Com relação à situação da língua espanhola no currículo das escolas estaduais ${ }^{3}$, vale mencionar que esta ainda encontra-se em fase de implementação no currículo oficial das escolas paulistas, tendo em vista o dispositivo legal da Lei Federal no $11.161^{4}$.

Partindo da concepção de currículo formulada por Goodson (1997), os conteúdos do Currículo+ relacionados à língua espanhola são considerados complementares ao currículo oficial, porém em nossa experiência de orientação e acompanhamento de atividades de ensino de espanhol em escolas estaduais do interior de São Paulo5, temos constatado que o Currículo+ pode ser pensado em uma perspectiva "invertida" (BERGMANN; SAMS, 2012), destinando o tempo em que os alunos estão fora da sala de aula para a realização de atividades que contribuam para a compreensão de fenômenos linguísticos, invertendo a lógica de que é na sala de aula que os alunos apreendem conteúdos.

O objetivo deste artigo, portanto, é discutir potencialidades dos recursos disponíveis na plataforma Currículo+ a serem exploradas por professores de língua espanhola por meio da abordagem de aula invertida (BERGMANN; SAMS, 2012), com vistas a contribuir para as discussões sobre a condiçóes que têm sido proporcionadas para o ensino dessa língua no estado de São Paulo.

\section{Princípios das "aulas invertidas" e possibilidades do Currículo+}

Partimos do pressuposto de que o uso de novas tecnologias sem modelos pedagógicos apropriados não produz melhorias no processo de ensino (SOTO; GREGOLIN; RANGEL, 2009). Nesse sentido, uma estratégia didática possível para a incorporação de tecnologias é a proposta de trabalhar "aulas invertidas" no ensino de línguas estrangeiras.

\footnotetext{
Não foi possível obter dados precisos sobre a oferta de aulas de espanhol na rede estadual.

4 Trata-se da Lei Federal no 11.161, que dispóe que "O ensino da língua espanhola, de oferta obrigatória pela escola e de matrícula facultativa para o aluno, será implantado, gradativamente, nos currículos plenos do ensino médio" no "prazo de cinco anos" a partir de 2005. Disponível em: <http://www.planalto.gov. br/ccivil_03/_Ato2004-2006/2005/Lei/L11161.htm>. Acesso em: 10 mar. 2016.

5 Mais especificamente, atividades desenvolvidas no âmbito de disciplinas de estágio supervisionado no curso de Letras e da coordenação de área no PIBID (Programa Institucional de Bolsas de Iniciação à Docência), com apoio financeiro da CAPES.
} 
O termo "aulas invertidas" tem sido utilizado no Brasil como traduçáo do termo Flipped Classroom, proposto por Bergmann e Sams (2012), que consiste na lógica da mentalidade de inversão daquilo que se faz em sala de aula: o aluno aprende em casa, de forma autônoma e previamente planejada pelo professor, interagindo com objetos educacionais e, em sala de aula, realiza outros tipos de atividades como forma de solucionar dúvidas e consolidar seu aprendizado. Segundo os autores:

Esperamos que enquanto você leia [este livro], você perceba que não há uma única maneira de inverter a sua sala de aula - não há tal coisa como $a$ sala de aula invertida. Não existe uma metodologia específica para ser replicada, não há uma lista a seguir que leve a resultados garantidos. Inverter a sala de aula significa muito mais uma mentalidade: redirecionar o foco de atenção do professor e focar o aluno e a aprendizagem ${ }^{6}$. (BERGMANN; SAMS, 2012, p.11, tradução nossa).

A proposta de inverter a lógica da sala de aula, atribuindo autonomia ao aluno diante de seu aprendizado e invertendo objetivos e papéis, não é novidade e talvez nem seja uma inovação no campo educacional. A crítica à "educação bancária" vem sendo feita desde a década de 70 no Brasil, quando P. Freire (1974) questionava a imposição de conteúdos pelos professores, numa concepção de que os alunos receberiam passivamente aquilo que lhes era depositado. Nesse sentido, compartilhamos da hipótese de que a autonomia pode favorecer o processo de aprendizado mais crítico.

Nesse contexto, o Currículo+ pode induzir professores e gestores a (re)criarem aquilo que fazem dentro e fora da sala de aula, "invertendo" os objetivos e açôes: ao estimularem que os momentos anteriores àqueles de permanência dos alunos na escola sejam também de aprendizado autônomo do aluno, conseguem otimizar o tempo do contato face-to-face da sala de aula.

Assim, ao serem (re)pensados tanto o currículo como as estratégias de ensino, a partir das potencialidades de cada tecnologia disponibilizada, surgem outras possibilidades de trabalho com as línguas nas redes de interação que se formam entre alunos fora do espaço da sala de aula.

No caso específico da língua espanhola, ao realizarmos breve pesquisa ${ }^{7}$ sobre recursos educacionais pelo mecanismo de busca da plataforma Currículo+, obtivemos o retorno de 20 itens relacionados com recursos educativos, especificados a seguir:

We also hope that as you read, you realize that there is no single way to flip your classroom - there is no such thing as the flipped classroom. There is no specific methodology to be replicated, no checklist to follow that leads to guaranteed results. Flipping the classroom is more about a mindset: redirecting attention away from the teacher and putting attention on the learner and the learning. (BERGMANN; SAMS, 2012, p.11).

7 A pesquisa restringiu-se à inserção do termo "língua espanhola" no mecanismo de busca, na data de 10/03/2016. 
a) 8 vídeo-aulas do projeto Telecurso, voltadas para o Ensino Médio (acesso aberto);

b) Curso Espanhol Online em parceria com o Universia (restrito com senha);

c) 2 Jogos de memória, sobre temáticas de "placas de trânsito em espanhol" e de "variantes linguísticas" (acesso aberto) e 1 Jogo que envolve operaçôes matemáticas.

d) 6 Vídeos, sobre as seguintes temáticas: locuções adverbiais, tutorial sobre HipHop, narração de um conto literário, cidadania olímpica, ciclo da água e falsos cognatos (acesso aberto);

e) 2 Infográficos, sobre regióes do Brasil e sobre outros países (acesso aberto).

Todos os recursos acompanham uma ficha, que apresenta detalhadamente os conteúdos do currículo oficial que podem ser explorados segundo os níveis e expectativas de aprendizagem. Levando em conta nosso objetivo de discutir as potencialidades de tais recursos na perspectiva de "inverter" a sala de aula de língua espanhola, interessa-nos destacar que nenhum dos recursos disponibilizados explora habilidades de produção e interação em língua estrangeira, pois focalizam habilidades de compreensão oral e escrita. Dessa forma, as propostas pedagógicas que pretendam utilizar estes recursos devem prever de que forma e em quais outros momentos e espaços as habilidades de produção podem ocorrer.

Uma possibilidade "invertida" ao explorar os vídeos disponíveis, por exemplo, é desenhar atividades fora da sala de aula que fomentem postura ativa e autônoma dos alunos, na busca por melhores compreensóes sobre as temáticas apresentadas, reservando o espaço da sala de aula para o debate e soluçáo de dúvidas, o que pode ser uma alternativa viável para explorar esse tipo de recurso do Currículo+ (vídeo-aulas) no contexto de ensino formal.

Nesse sentido, as distintas formas de navegação na web instauram a possibilidade de que cada aluno percorra um itinerário distinto para chegar ao mesmo resultado, o que evidencia que o processo de aprendizado pode ocorrer de forma diferente para cada um sem prejuízo dos resultados alcançados.

Outra potencialidade dos recursos disponíveis é explorar o mecanismo de publicaçáo de comentários nos vídeos disponíveis no Youtube, o que pode fomentar discussôes posteriores em sala de aula sobre recursos e estratégias de cortesia e socialização em língua espanhola, por exemplo. Vale destacar que a cultura digital baseia-se na ideia de que qualquer sujeito pode ser produtor de conteúdos e compartilhá-los.

No contexto de uso da língua estrangeira, quando o aluno é incentivado a comentar a produção de outro, em realidade está desenvolvendo atividade de pesquisa e avaliação sobre o trabalho alheio, que envolve leitura e interpretação e posterior produção, com a função social de uma escrita que respeita e valoriza o trabalho intelectual de autoria. 
Ao explorar o vídeo que trata de conceito gramatical do Currículo+, por exemplo, uma possibilidade "invertida" é propor um problema de uso de língua para o qual os alunos devam buscar soluçóes antecipadamente, o que pode favorecer o desenvolvimento de criticidade, iniciativa na busca e seleção de informaçóes, autonomia na apropriação de conhecimentos, trabalho em equipe para a resolução de problemas, dentre outras possibilidades.

Por meio da estratégia de aula invertida, a construção teórica sobre conceitos gramaticais pode iniciar-se antes da aula presencial, com recursos digitais, em um processo de apropriação dos conteúdos por parte dos alunos dos conteúdos, que depois serão trabalhados em seus aspectos teóricos e práticos na sala de aula.

As atividades desenvolvidas em meio online com mediação didática, na perspectiva invertida que estamos discutindo, podem contribuir para a apropriaçáo da língua estrangeira que foge à abordagem meramente instrumental, uma vez que implicam necessariamente que os alunos busquem soluçóes para resolução de problemas e construam de forma mais ativa os conhecimentos, deslocando o professor da posição do centro do processo.

Os jogos disponíveis atualmente no Currículo+ para a língua espanhola oferecem a possibilidade de estimular o aprendizado por meio do processo de "gamificação" (GEE, 2004), que consiste na utilização de jogos de forma integrada ao currículo. Dessa forma, a exploração pelos alunos dos jogos disponíveis pode favorecer processos de engajamento dos alunos com o próprio processo de aprendizado, além de possibilitar o contato inicial com conteúdos da língua estrangeira de forma integrada com outros conteúdos do currículo, em uma abordagem interdisciplinar.

Ao se apropriarem das regras/instruçóes e participarem desses jogos na língua estrangeira, os alunos podem experimentar oportunidades de comunicaçáo que ultrapassam a repetição formal de estruturas e, nesse sentido, há possibilidades interessantes para que o professor trabalhe aspectos da relação entre a língua materna e a estrangeira, por exemplo.

Os infográficos disponíveis em língua espanhola no Currículo+ também oferecem a possibilidade de que se trabalhe na perspectiva de desenvolver novos letramentos pois, seguindo Coscarelli (2005, p.29), na atualidade para ser considerado letrado, o aluno precisa, além de ler, ser "bom navegador e digitador" e, dessa forma:

A escola precisa encarar seu papel, náo mais apenas de transmissora de saber, mas de ambiente de construção do conhecimento. Os alunos precisam saber aprender, saber onde encontrar as informaçóes de que precisam e ter autonomia para lidar com essas informaçóes, avaliando, questionando e aplicando aquelas que julgarem úteis e pertinentes. Para isso, é preciso que a escola abra mão de um conteúdo ou uma matéria rigidamente determinada e seja capaz de administrar a flexibilidade exigida daqueles que querem adotar uma postura de construção de conhecimento. (COSCARELLI, 2005, p.32). 
Para que seja possível cumprir com esse papel, a formação dos professores objetiva fugir "[...] da instrumentalização dos alunos e busca aliar aspectos teóricos às práticas, considerando os contextos e os atores inseridos." (SOTO; GREGOLIN; ROZENFELD, 2013, p.280). Em oposição a um modelo de formação baseado no treinamento de professores, nosso projeto de formação docente considera o processo de construção das identidades a partir das opçóes tomadas, das práticas desenvolvidas, da forma como se mobilizam os conhecimentos e saberes, partindo dos questionamentos propostos por Moreira (2001) sobre se:

No caso particular da formação de professores cabe indagar: que professores estão sendo formados, por meio dos currículos atuais, tanto na formaçáo inicial como na formação continuada? Que professores deveriam ser formados? Professores sintonizados com os padróes dominantes ou professores abertos tanto à pluralidade cultural da sociedade mais ampla como à pluralidade de identidades presente no contexto específico em que se desenvolve a prática pedagógica? Professores comprometidos com o arranjo social existente ou professores questionadores e críticos? Professores que aceitam o neoliberalismo como a única saída ou que se dispóem tanto a criticá-lo como a oferecer alternativas a ele? Professores capazes de uma ação pedagógica multiculturalmente orientada? (MOREIRA, 2001, p.5).

$\mathrm{Na}$ perspectiva das novas tecnologias, cabe questionarmos os impactos destas sobre os currículos e as práticas docentes. Talvez o impacto mais imediato causado pelo uso das novas tecnologias no ensino de língua espanhola seja abrir a sala de aula para o mundo, oferecendo aos professores possibilidades de atuação mais autônoma, oferecendo aos alunos oportunidades para desenvolverem habilidades em colaboração com outros, enquanto práticas efetivas de uso da língua.

Ao mesmo tempo, implica maior necessidade de que os professores invistam tempo e energia, assumindo para si a tarefa de produção de conteúdos educacionais, em colaboração com colegas, em rede e que também contribuam com avaliação sobre o uso dos recursos, no processo de retroalimentação das plataformas e repositórios. Nesse processo, talvez tenham condiçóes de se posicionarem como autores e não meros consumidores de conteúdos produzidos por outros, o que supóe uma mudança de paradigma que pode contribuir para valorização social da profissão, reposicionando os professores como intelectuais e produtores de teorias.

\section{TECHNOLOGIES TO FLIP THE CLASSROOM: POSSIBILITIES OF CURRÍCULO + FOR SPANISH LANGUAGE LEARNING IN SAO PAULO}

- ABSTRACT: This article discuss the concept of "new technologies" in the context of digital Nativity (PRENSKY, 2011a). We assume that digital technologies allows new ways of relationship between 
space and time and changes our ways of socializing on the web, which demand new pedagogical proposals. Therefore, we present a review of some activities of Curriculo + platform, provided by the Secretaria Estadual de São Paulo, as technologies with the potential to be explored by teachers of Spanish language through flipped class approach (BERGMANN and SAMS, 2012). We also discuss the need for teachers to take for themselves the educational content production task, in collaboration with colleagues, and contribute to evaluation of the use of resources in the process of feedback platforms and repositories.

- KEYWORDS: Technologies. Spanish. Flipped classroom. Curriculum+.

\section{REFERÊNCIAS}

BERGMAN, J.; SAMS, A. Flip your classroom: reach every student in every class every day. Virginia: ISTE, 2012.

COSCARELLI, C. V. Alfabetização e letramento digital. In: COSCARELLI, C. V.; RIBEIRO, A. E. (Org.). Letramento digital: aspectos sociais e possibilidades pedagógicas. Belo Horizonte: Autêntica, 2005. p.25-40.

FREIRE, M. M. Formação tecnológica de professores: problematizando, refletindo, buscando... In: SOTO, U., MAYRINK, M. F.; GREGOLIN, I. V. (Org.). Linguagem, educaçáo e virtualidade. São Paulo: Ed. da UNESP; São Paulo: Cultura Acadêmica, 2009. Disponível em: <http://static.scielo.org/scielobooks/px29p/pdf/soto-9788579830174.pdf>. Acesso em: 10 mar. 2016.

FREIRE, P. Pedagogia da autonomia. Saberes necessários à prática educativa. Sáo Paulo: Paz e Terra, 1996.

FREIRE, P. Pedagogia do oprimido. Rio de Janeiro: Paz e Terra, 1974.

GEE, J. P. Learning by design: Games as learning machines. Interactive Educational Multimedia, Barcelona, n.8, p.15-23, 2004. Disponível em: <http://www.raco.cat/index.php/ IEM/article/download/204239/272773>. Acesso em: 08 fev. 2016.

GOODSON, I. Currículo: teoria e história. Petrópolis, RJ: Vozes, 1997.

IMBERNÓN, F. Formaçáo docente e profissional: formar-se para a mudança e a incerteza. São Paulo: Cortez, 2000.

KENSKI, V. M. Educaçáo e tecnologias: o novo ritmo da informação. São Paulo: Papirus, 2007.

LEFFA, V. J. A aprendizagem de línguas mediada por computador. In: LEFFA, V. (Org.). Pesquisa em lingüística aplicada: temas e métodos. Pelotas: Educat, 2006. p. 11-36. 
MCLUHAN, M. McLuhan por McLuhan: entrevistas e conferências inéditas do profeta da globalização. Rio de Janeiro: Ediouro, 2005.

MCLUHAN, M.; FIORE, Q. Os meios são as massagens: um inventário dos efeitos. São Paulo: Record, 1969. Disponível em: <https://dodopublicacoes.files.wordpress.com/2009/02/ osmeiosmassagens.pdf>. Acesso em: 10 abr. 2016.

MOREIRA, A. F. B. Currículo, cultura e formação de professores. Educar, Curitiba, n. 17, p.39-52, 2001. Disponível em: <http://www.educaremrevista.ufpr.br/arquivos_17/barbosa_ moreira.pdf>. Acesso em: 10 dez. 2014.

PAIVA, V. L. M. O. A pesquisa sobre interação e aprendizagem de línguas mediadas pelo computador. Calidoscópio, São Leopoldo. v. 3, n.1, p.5-12, jan./abr. 2005.

PRENSKY, M. From digital natives to digital Wisdom. 2011a. Disponível em: <http:// marcprensky.com/writing/Prensky-Intro_to_From_DN_to_DW.pdf>. Acesso em: 13 fev. 2016.

PRENSKY, M. Enseñar a nativos digitales. Madrid: Ediciones SM, $2011 \mathrm{~b}$.

SOTO, U.; GREGOLIN, I. V.; RANGEL, M. Concepção, design e ferramentas de um ambiente virtual colaborativo de ensino-aprendizagem de língua espanhola. In: SOTO, U.; MAYRINK, M.; GREGOLIN, I. V. (Org.). Linguagem, educação, virtualidade: experiências e reflexôes. São Paulo: Cultura Acadêmica, 2009. p.117-134.

SOTO, U.; GREGOLIN, I. V.; ROZENFELD, C. A Formação inicial de professores de línguas: ações virtuais colaborativas para a articulação teoria-prática-reflexão. In: SILVA, K. A. et al. (Org.). A formação de professores de línguas: novos olhares. Campinas: Pontes, 2013. v. 2. p. 259-280.

SOTO, U., MAYRINK, M. F.; GREGOLIN, I. V. (Org.). Linguagem, educação e virtualidade. São Paulo: Ed. da UNESP; São Paulo: Cultura Acadêmica, 2009. Disponível em: <http://static.scielo.org/scielobooks/px29p/pdf/soto-9788579830174.pdf>. Acesso em: 10 mar. 2016.

TOMAZELLA, C. M. Ensino de LE em ambientes virtuais: um estudo sobre os tipos de interação e de andaimes presentes na construção de conhecimento em língua espanhola. 2013. 85f. Dissertação (Mestrado em Linguística) - Universidade Federal de São Carlos, São Carlos, 2013. Disponível em: <https://repositorio.ufscar.br/handle/ufscar/5757?show=full>. Acesso em: 10 mar. 2016.

Recebido em 15/06/2016

Aprovado em 28/08/2016 
